\title{
WORIPLLBE SOLDIONS
}

\section{Conducting a Periodic Inspection for Each Procedure in a Hazardous Energy Control (Lockout/Tagout) Program}

\section{Summary}

Employers are required by $29 \mathrm{CFR}^{*} \$$ $1910.147(c)(6)$ to conduct a periodic inspection of written hazardous energy control (lockout/tagout) procedures. The inspection must be performed at least once annually [per 12-month interval, as stated in 1910.147(c)(6)(i)] because of the significant risks associated with inadequate energy control procedures or the failure to properly implement them [OSHA 2008].

In accordance with the Occupational Safety and Health Administration (OSHA) standard, the National Institute for Occupational Safety and Health (NIOSH) recommends best

"Code of Federal Regulations. See CFR in References. practices for conducting an annual periodic inspection of each energy control procedure, as part of an energy control (lockout/tagout) program.

Legal requirements are established in 29 CFR $\$ 1910.147$ and their enforcement is described in the OSHA document The Control of Hazardous Energy-Enforcement Policy and Inspection Procedures. OSHA Instruction Directive No. CPL 02-00-147 [OSHA 2008]. However, compliance with the regulations is based solely on the CFR. No wording in this document, national standards, the directive or other document supersedes the requirements in the CFR.

\section{Introduction}

A required component of an effective energy control program [29 CFR $1910.147(c)(1)]$ is an annual periodic inspection for each piece of equipment requiring lockout and tagout ${ }^{\dagger}$

${ }^{\dagger}$ OSHA standards require the use of either lockout or tagout. However, NIOSH [1999] procedures in the work environment. The periodic inspection process evaluates the adequacy of the procedures and the ability of the authorized employee to follow the

recommends that any hazardous control program include both lockout and tagout to ensure maximum protection. Also note that some state plans may have more stringent requirements that those found in 29 CFR 1910.147

procedures. An authorized employee is defined in 29 CFR 1910.147(b) as a person who locks out or tags out machines or equipment in order to perform servicing or maintenance on that machine or equipment. The lockout and tagout procedures for each piece of equipment must be accurate and followed, in proper sequence, to prevent severe injury and death.

All equipment installed, replaced, or having had a major repair, renovation, or modification after January 2, 1990, must be designed to accept a lockout device. In accordance with 29 CFR 1910.147(c)(3)(i) and (ii), tagout devices can only be used as energy isolating device on equipment that is capable of being locked out if the employer can demonstrate that a level of safety is achieved in the tagout program which is equivalent to the level of safety obtained by using a lockout program. As a best practice, NIOSH recommends the application of a lockout device and a tag with the identity of the authorized employee performing the work.

Hazardous energy releases can occur during the installation, maintenance, service, unexpected start up, or repair of machinery and equipment. Common

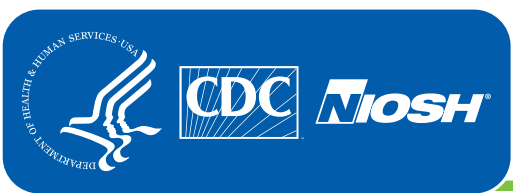

Centers for Disease Control

and Prevention

National Institute for Occupational

Safety and Health 


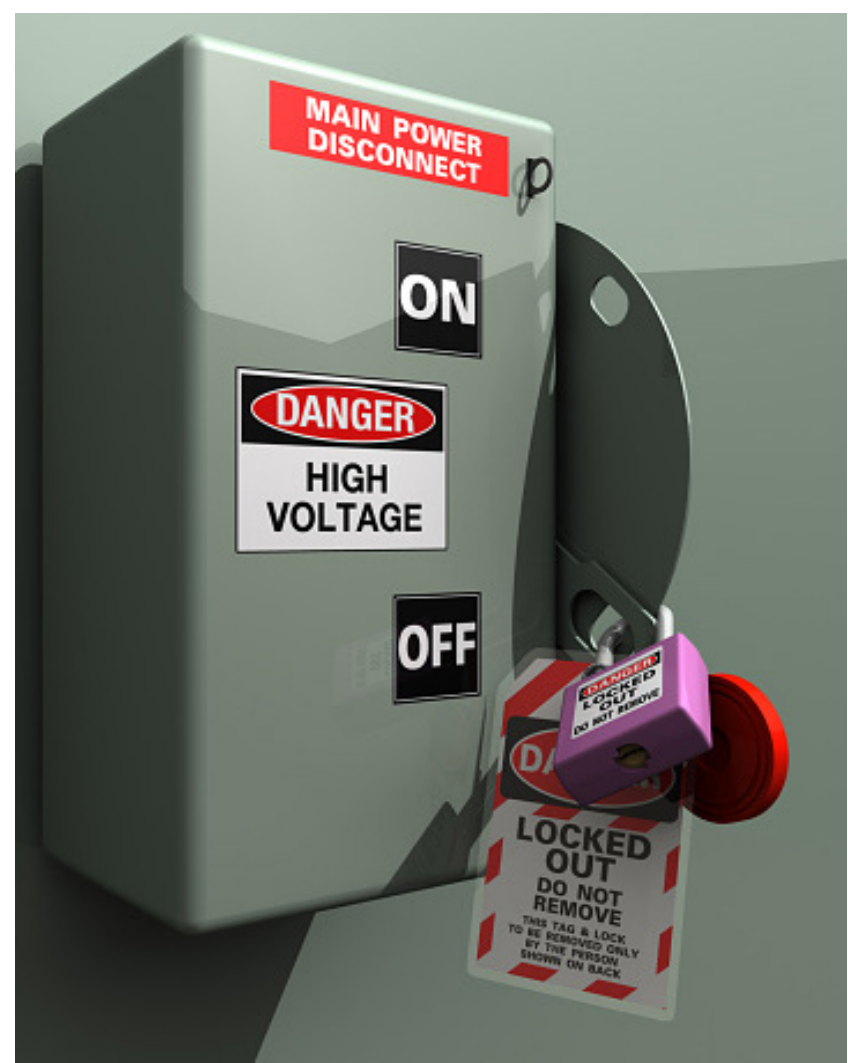

examples of stored energy sources include electrical, mechanical, hydraulic, gravity, steam, pneumatic, chemical, thermal, and gas. Workers are at risk of severe injury and death during equipment or machine maintenance and servicing if proper lockout/tagout procedures are not accurate or not followed [NIOSH 1999].

NIOSH previously recommended developing and implementing a hazardous energy control program including lockout and tagout procedures and worker training to prevent such incidents [NIOSH 1999, 2011]. This document recommends best practices for carrying out the annual periodic inspection as specified in 29 CFR 1910.147(c)(6)(i) through (ii).

\section{Description of Exposure}

In the United States, three million workers are at risk of serious injury or death if hazardous energy control procedures (lockout/tagout) are not properly executed [OSHA n.d.]. Workers may experience serious injury or death from the unexpected startup or release of equipment/machinery containing stored energy.

From 2018 to 2020, more than 160 injuries and fatalities involving lockout and tagout of hazardous energy sources were reported in the OSHA Information System database. ${ }^{\ddagger}$ These

\footnotetext{
*Fatality and Catastrophe Investigation Summaries, (OSHA 170 form), are developed after OSHA conducts an inspection in response to a fatality or
}

incidents involved electrocutions, amputations, entanglement, crushing between machine parts, and being struck by objects while employees were servicing machines or clearing jams [OSHA n.d.; 29 CFR 1910.147(a)(2)].

\section{Case Study 1}

In cooperation with the NIOSH Fatality Assessment and Control Evaluation (FACE ${ }^{\S}$ ) Program, the Oregon Health \& Science University [Oregon State FACE' Program 2019] investigated a fatality in which a technician was training a new employee to perform routine preventive and/or scheduled maintenance on a vertical storage machine. A roller used to support a carrier tray fell out, and the technician could not reinstall it from outside the machine. A carrier tray was removed to provide space for him to enter the unit. The technician climbed inside to lie on another carrier below the removed carrier. As the trainee cycled the machine to put the technician in a position to access and reinstall the roller, the machine malfunctioned. The technician asked the trainee to make another input to the controls. The machine advanced the technician over the top of the vertical storage unit, which had very limited space. The technician was crushed and killed.

From the investigation, contributing factors to the incident included (1) failure to apply lockout and tagout procedures, (2) inadequate knowledge of safer methods to perform the work (i.e., options to rotate carriers without power), and (3) inadequate training and communication regarding specific job hazards [Oregon State FACE Program 2019].

Investigators recommended the following:

- Periodic inspections of lockout/tagout procedures at least annually 29 CFR 1910.147(c)(6)

- Following lockout/tagout procedures to reduce the risk of hazardous movement of machines (29 CFR 1910.147)

catastrophe. The summaries provide a complete description of the incident, generally including events leading to the incident and causal factors. These summaries can be easily searched by keyword, text in the summary description, event date, and industry (SIC). Information may also be obtained for specific investigation(s), (Insp Nr). Summaries currently available include completed investigations from 1984 through 1 year earlier than today's date. Summaries for later dates are not included to provide time for OSHA staff to complete the investigation and revise the summary as necessary. Furthermore, summaries must undergo a process for screening personal information and adding keywords that may cause some additional delay in posting [OSHA n.d.].

'Investigations conducted through the FACE program allow the identification of factors that contribute to fatal injuries at work. This information is used to develop comprehensive recommendations for preventing similar deaths [NIOSH 2021].

'Oregon has an OSHA State Plan. State Plan regulations must be at least as effective as Federal OSHA's (29 CFR 1910.147 for lockout/tagout), but they are codified according to the state's legislative practices. Oregon OSHA's lockout/tagout regulation is Rule Number 437-002-2303. Employers should check with their regulator for details if they are in a State-Plan state. 
- Routine assessment of job hazards and employees' knowledge of control hazards (29 CFR 1910.147)

- Regular, periodic training and communications related to on site-specific hazards (such as potential sources of hazardous energy release) and safe work practices

\section{Case Study 2}

In cooperation with the NIOSH FACE Program, the California Department of Public Health [CA FACE ${ }^{* *} 2016$ ] investigated a fatality in which a foreman was crushed between moving parts of a baling machine while he was clearing debris out of the machine. ${ }^{\dagger \dagger}$

Portions of the machine's moving parts, including the magazine area, were enclosed by a six-foot metal enclosure with access gates. The access gates were equipped with an interlock sensor so that the machine would shut off when the gates were opened. The hay baler was installed at the company by the manufacturer. The hay baler operator controlled the machine at a computerized panel. A bale of hay was automatically loaded onto the hay baler, to be resized. The bales were compressed, tied, weighed, and removed for storage and shipment. A magazine kicker arm moved the hay bale to an area for pickup after it had been compressed and tied. The baling machine used electrical and hydraulic energy to operate (a multi-energy source piece of equipment).

Before the incident, the victim told the machine operator that he was going to clean the baler with compressed air. The victim likely entered the magazine area through the access gate. It is not known whether the victim disabled the interlock sensor so the machine would not shut off when he opened the gate. The machine operator stated that he was at the control panel at the time of the incident; he was not aware that the victim was in the magazine area. A forklift operator noticed the victim in the magazine area between the kicker arm and the magazine frame. The kicker arm was manually operated to release the victim. The machine did not shut down at the time of the incident. The victim was transported to a hospital where he died from his injuries.

The company had not developed or implemented a written hazardous energy control program including specific procedures for locking out equipment to include the hay bal-

\footnotetext{
California has an OSHA State Plan. State Plan regulations must be at least as effective as Federal OSHA's (29 CFR 1910.147 for lockout/tagout or 29 CFR 1928.57 Guarding of farm field equipment, farmstead equipment, and cotton gins), but they are codified according to the state's legislative practices. Cal OSHA's lockout/tagout regulation is $\mathrm{Ti}$ tle $8 \$ 3314$. Employers should check with their regulator for details if they are in a State-Plan state.

"29 CFR 1910.147 doesn’t specifically apply to agriculture or construction, but this case study is included here as an example of (1) equipment with multiple sources of energy and (2) the need for hazardous energy control procedures that demonstrate good safety practices.
}

ing machine. Specific written procedural steps for shutting down, isolating, blocking, and securing machines or equipment to control hazardous energy are required for equipment that has multiple sources of energy. The California FACE investigator recommended developing and implementing a comprehensive hazardous energy control program including lockout/tagout procedures and training [CA FACE 2016].

\section{Recommendations for Best Practices in Implementation}

The periodic inspection is an audit/evaluation that provides a vital measure for worker safety by ensuring that proper lockout and tagout sequence is performed on each specific piece of equipment and that the written procedure is accurate. The following are best practices for implementing the legal requirement for an annual inspection.

\section{General Information}

- At a minimum, the periodic inspection process must contain two components:

- an inspection of each energy control procedure and

- a review of each authorized employee's responsibilities under the energy control procedure being inspected [OSHA 2008].

- The goal of the periodic inspection is to

- verify that the procedures are adequate by ensuring that all energy sources are identified and controlled, de-energized, or otherwise made safe,

- verify that the procedures are being properly applied,

- ensure that the employees involved are familiar with their responsibilities,

- ensure that the employees maintain proficiency in the energy control procedures that they are (individually) responsible for [OSHA 2008], and

- identify inaccuracies and deficiencies to correct them.

- The periodic inspection process will ascertain whether

- the steps in the written procedures are being followed,

- the employees know how to follow the written procedures, and

- the written procedures provide the necessary protections [OSHA 2008] 
- Energy control procedures used less frequently than once annually (per 12-month interval) must be inspected only when used [OSHA 2008].

\section{Inspection}

- The annual periodic inspection may be achieved through planned visual observations, random audits, or plant safety tours [OSHA 2008].

- A periodic inspection must include a demonstration of the procedures and must be performed while the authorized employee performs service/maintenance on machine/equipment [OSHA 2008].

- Each energy control procedure must be separately inspected to ensure that the procedure is adequate and is properly implemented by the authorized employee [OSHA 2008].

- Employers must certify that the inspections were performed. The certification must specify the following [OSHA 2008]:

- The machine/equipment on which the energy control procedure was used

- The date of the inspection

- The name(s) of the employee(s) included in the periodic inspection

- The name(s) of the inspector(s).

\section{Equipment that Requires Written Procedures}

- As outlined in 29 CFR $\$ 1910.147$, procedures shall be developed, documented, and used for the control of hazardous energy when ANY of the following elements exist:

- The machine or equipment has the potential for stored or residual energy or re-accumulation of stored energy after shutdown.

- The machine or equipment has a single energy source that is not readily identifiable or capable of being isolated. (Example: An electrical knife switch disconnect, that is not labeled and is located away from the equipment in a motor [mechanical] control center room or other location, would not be readily identifiable.)

- The isolation and locking out of that energy source does not completely deenergize and deactivate the machine or equipment.

- The machine or equipment is not isolated from that energy source and is not locked out during servicing or maintenance.

- A single lockout device will not achieve a lockedout condition.
- The lockout device is not under the exclusive control of the authorized employee performing the servicing or maintenance.

- The servicing or maintenance creates hazards for other employees.

- The employer has had an incident involving the unexpected activation or re-energization of the machine or equipment during servicing or maintenance.

\section{Written Energy Control Procedures}

- Written energy control procedures should contain elements such as

- the scope of the procedures,

- the intended purpose,

- the names of authorized personnel,

- rules for shift change, transfer of locks, etc., and

- specific methods used to control hazardous energy.

\section{Grouping Equipment}

- An employer can group equipment-specific lockout/ tagout procedures into one procedure to comply with the standard [OSHA 2008].

- If equipment is categorized into the same group, the equipment/machinery must have a similar type, energy source, or energy control measures [OSHA 2008].

- A grouping of individual procedures would be considered one procedure for periodic inspection purposes [OSHA 2008].

- If there are variations in the type, energy source, or energy control methods, it is recommended that specific, individualized procedures be developed [OSHA 2008].

- The employer should verify that the energy control procedure has not changed in a manner that is no longer covered by the group procedure.

\section{Inspector/Authorized Employee}

- The inspector must be a lockout/tagout-authorized employee who is knowledgeable and is NOT currently performing lockout/tagout on the energy control procedure actively being inspected. The inspector cannot implement any part of the procedure during the inspection.

- The inspector must observe the implementation of the energy control (lockout/tagout) procedure for the equipment/machine being evaluated and talk with at least one authorized employee who is implementing the procedure, to ensure the employee understands the procedure [OSHA 2008]. 
- The inspector can either observe a representative number of employees implementing the procedure on the equipment or talk with all other authorized employees who implement the procedure, even though they may not be observed implementing the procedure. ${ }^{\ddagger}$

\section{Training}

- If the periodic inspection process reveals deviations from the written procedures or inadequacies in an employee's knowledge of the procedures, the employee must be retrained [OSHA 2008].

- Adequate and thorough retraining must be conducted to expand the employee's knowledge of the procedures and to ensure the employee is capable of fully implementing the procedures in the appropriate sequence.

\section{Acknowledgments}

This document was prepared by Sarah Hughes, Division of Science Integration (DSI); Jeffrey Funke, Division of Safety Research; and Susan Afanuh (DSI), NIOSH.

\section{Suggested Citation}

NIOSH [2021]. Conducting a periodic inspection for each procedure in a hazardous energy control (lockout/tagout) program. By Hughes S, Funke J, Afanuh S. Cincinnati, OH: U.S. Department of Health and Human Services, Centers for Disease Control and Prevention, National Institute for Occupational Safety and Health, DHHS (NIOSH) Publication No. 2022-106, https://doi.org/10.26616/NIOSHPUB2022106.

\section{References}

CA FACE [2016]. A foreman dies when he is crushed in a hay baling machine. Richmond, CA: California FACE Program, California Department of Public Health, Occupational Health Branch, Case Report 16CA002. FACE Program: California Case Report 16CA002 | NIOSH | CDC.

\footnotetext{
\#The OSHA [2008]. Compliance Directive indicates a representative number is typically defined as $25 \%$ of the $\mathrm{LO} / \mathrm{TO}$-authorized employees.
}

CFR. Code of Federal regulations. Washington, DC: U.S. Government Printing Office, Office of the Federal Register.

NIOSH [1999]. Preventing worker deaths from uncontrolled release of electrical, mechanical, and other types of hazardous energy. NIOSH Alert. Cincinnati, OH: U.S. Department of Health and Human Services, Centers for Disease Control and Prevention, National Institute for Occupational Safety and Health, https://www.cdc.gov/niosh/docs/99110/pdfs/99-110.pdf?id=10.26616/NIOSHPUB99110.

NIOSH [2011]. Using lockout and tagout procedures to prevent injury and death during machine maintenance. Workplace Solutions. Cincinnati, OH: U.S. Department of Health and Human Services, Centers for Disease Control and Prevention, National Institute for Occupational Safety and Health, https://www.cdc.gov/niosh/docs/wp-solutions/2011-156/pdfs/2011-156.pdf?id=10.26616/NIOSHPUB2011156.

NIOSH [2021]. Fatality Assessment and Control Evaluation (FACE) Program. Cincinnati, OH: U.S. Department of Health and Human Services, Centers for Disease Control and Prevention, National Institute for Occupational Safety and Health, https://www.cdc.gov/niosh/face/default.html.

Oregon State FACE Program [2019]. Maintenance mechanic crushed working inside of a vertical storage machine. Portland, OR: Oregon Institute of Occupational Health Sciences, Oregon Health and Science University, Report No. 201722-1, https://www.cdc.gov/niosh/face/stateface/or/17or022. html.

OSHA [2008]. The control of hazardous energy-enforcement policy and inspection procedures. OSHA Instruction. Washington, DC: U.S. Department of Labor, Occupational Safety and Health Administration, Directive No. CPL 02-00-147, https://www.osha.gov/sites/default/files/ enforcement/directives/CPL_02-00-147.pdf.

OSHA [no date]. Fatality and catastrophe investigation summaries. Washington, DC: U.S. Department of Labor, Occupational Safety and Health Administration, https://www. osha.gov/pls/imis/accidentsearch.html. 


\section{For More Information}

Find NIOSH products and get answers to workplace safety and health questions:

1-800-CDC-INFO (1-800-232-4636)

TTY: 1-888-232-6348

CDC/NIOSH INFO: cdc.gov/info | cdc.gov/niosh

Monthly NIOSH eNews: https://www.cdc.gov/niosh/enews/

Mention of any company or product does not constitute endorsement by NIOSH. In addition, citations to websites external to NIOSH do not constitute NIOSH endorsement of the sponsoring organizations or their programs or products. Furthermore, NIOSH is not responsible for the content of these websites.
This document is in the public domain and may be freely copied or reprinted. NIOSH encourages all readers of the Workplace Solutions to make them available to all interested employers and workers.

As part of the Centers for Disease Control and Prevention, NIOSH is the Federal agency responsible for conducting research and making recommendations to prevent workrelated illnesses and injuries. All Workplace Solutions are based on research studies that show how worker exposures to hazardous agents or activities can be significantly reduced.

DOI: https://doi.org/10.26616/NIOSHPUB2022106

DHHS (NIOSH) Publication No. 2022-106

December 2021

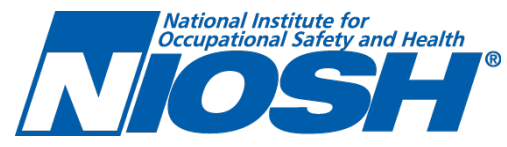

